\title{
Vaginal Perforation
}

National Cancer Institute

\section{Source}

National Cancer Institute. Vaginal Perforation. NCI Thesaurus. Code C78702.

A rupture in the vaginal wall due to traumatic or pathologic processes. 